\title{
MATHEMATICS TEACHER'S PERCEPTIONS ABOUT INFLUENCE OF DIFFERENT ICT USAGE STRATEGIES ON THEIR COMPETENCIES
}

\author{
EUGEN LJAJKO ${ }^{1 *}$ \\ ${ }^{1}$ Faculty of Sciences, University in Priština - Kosovska Mitrovica, Kosovska Mitrovica, Serbia
}

\begin{abstract}
Teacher competencies are among the key factors of a successful mathematics instruction. The main goal of the study was to compare teachers' beliefs and attitudes affected by different strategies in organizing the instruction process. The study gives a comparison of teachers' competencies in three groups of teachers - one teaching mathematics without ICT, the second using ready-made GeoGebra applets and the third one developing their own GeoGebra applets in cooperation with their students. The survey includes 65 mathematics teachers working in 21 primary and secondary schools in southern regions of Serbia. We observed, assessed and compared affectivemotivational characteristics of teachers - their beliefs and professional motivation. Results indicate that the teachers' affective-motivational characteristics depend on the way they employ technology in representing the content they teach. If the technology is used in an inappropriate manner it can impede the students' creativity, but it also obstructs teachers in deploying their full abilities in the process. The results also bring to the fore issues concerning ways to maintain positive effects achieved through ICT empowered instruction organized in the way the third group of teachers did.
\end{abstract}

Keywords: GeoGebra, Dynamic worksheets, Teachers' competencies, Learning environments.

\section{INTRODUCTION}

One of the goals of the $21^{\text {st }}$ century education is to fulfill needs of modern society for experts ready to cope with various problems that will be current in the future. Mathematics instruction is no exception. There are many aspects of the instruction that can contribute in fulfilling these tasks and others that can lead students and teachers develop habits not in line with the modern society needs.

Modern day instruction undoubtedly relies on InformaticsCommunication Technologies (ICT) usage. A number of studies dealt with influence that ICT usage in Mathematics instruction can have on students' creativity, knowledge building, quality of knowledge and their academic achievements. Some of them suggest that ICT usage in the Mathematics instruction can boost students' parameters (Arbain \& Shukor, 2015; Brown, 2010; Hopper, 2009; Rajagopal et al., 2015), but there are more studies (Bennett \& Maton, 2010; Bullen et al., 2011; Oblinger \& Oblinger, 2005; White \& Le Cornu, 2011) showing that the context is the key factor in understanding quality and efficiency of ICT impact on students' parameters.

One of the most important aspects of the ICT usage in the instruction process is that it requires teachers be able to meaningfully incorporate a new technology into the process. Several studies (Tatar, 2013; Zakaria \& Lee, 2012; Senk et al., 2012) indicate that using ICT in instruction process helps teachers improve and diversify their teaching techniques. Others

\footnotetext{
* Corresponding author: eugen.ljajko@pr.ac.rs

(Jimoyiannis, 2010; Kelly, 2002) point at an urgent need to coordinate students' interests and teachers' competencies in ICT learning environment. This study explores whether the way ICT are used in the Mathematics instruction can have impact on teachers' competencies.

Teachers' competencies. A successful teacher can be recognized through developed teachers' competencies. Though there are different approaches to describing the competencies, we based our study on the framework given in Döhrmann et al. (2012). There (ibid., p.327), the teachers' competencies are classified into two facets: cognitive abilities and affectivemotivational characteristics, Figure 1.

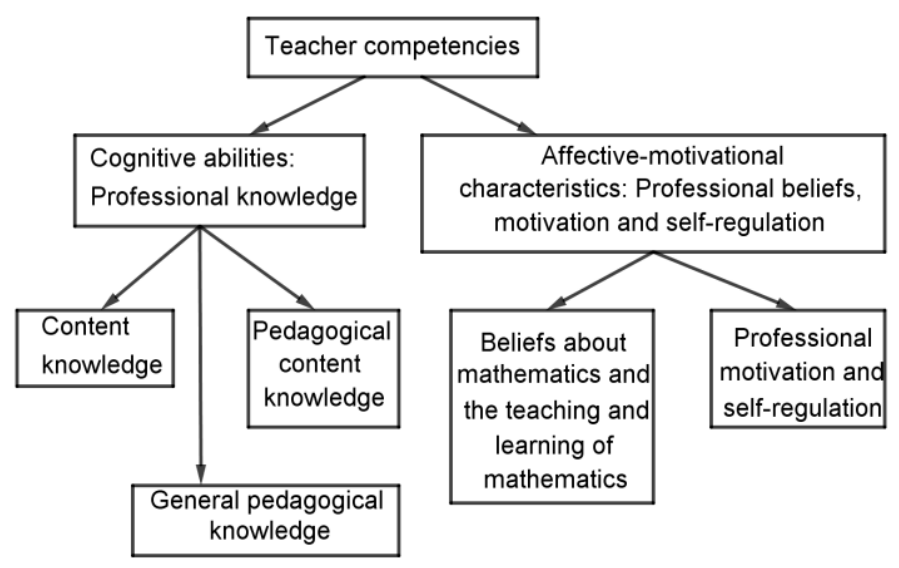

Figure 1. Teachers' professional competencies, according to Döhrmann et al. (2012). 
Both, teachers and students show changes in their classroom interactions when the instruction is ICT-empowered. The interactions tend to move towards more informal group work (Farrell, 1996). Fuglestat et al. (2010) came to a conclusion that "by involving teacher in all stages of the design process, the full extent of the repercussions involved in using digital tools in the classroom - their impact on not only students' learning and teachers' didactic approaches but also on classroom management, on teaching time, and on mathematical knowledge itself - becomes more apparent. (p.309)" Teachers develop their cognitive abilities mostly in their pre-service period, but their affective-motivational characteristics can be susceptible during their lifetime. Goos et al. (2010) state that "teacher characteristics (their mathematical and pedagogical knowledge, beliefs and attitudes) ... influence the integration of digital technologies into mathematics teaching." (ibid. p. 327). On the other hand, the influence that ICT usage can have on teachers' characteristics is poorly investigated. Therefore, we paid attention at teachers' affective-motivational characteristics and assessed the impact that the quantity and quality of ICT usage in the Mathematics instruction can have on this set of competencies.

About GeoGebra. In order to explore and assess impact that ICT usage can have on teachers' beliefs and attitudes, we introduced GeoGebra software into the instruction process - i.e. some of the teachers included in the survey organized their lessons using it. GeoGebra was chosen due to its ease of use and popularity among Serbian students and teachers. It is an open source dynamic mathematics software. Its interaction window has many different perspectives - algebra and graphics windows, spreadsheet, CAS, 3D graphics, etc. Work with GeoGebra is mostly organized through building worksheets - GeoGebra applets.

There are studies showing that teachers express very positive attitudes toward using GeoGebra in mathematics instruction (Hohenwarter et al., 2008, Preiner, 2008, Zakaria \& Lee, 2012), but they do not compare and assess different approaches to introduce technology into the instruction process. Teachers included in our research used two types of GeoGebra applets - ready-made or the ones developed by themselves in cooperation with their students. The ready-made applets were developed earlier, and the teachers were offered to incorporate them into the instruction process. Another group of teachers was consisted of the ones that had previous experience with GeoGebra, and they were required to develop their own applets. In that process they used to include their students, mostly through homework.

\section{METHOD}

Sampling. The sample was comprised of 65 mathematics teachers from 21 primary and secondary schools in southern regions of Serbia. According to the way they organized instruction process and level of ICT usage, the teachers were divided into three groups: those teaching mathematics without ICT - 41 teachers, the ones teaching mathematics using readymade GeoGebra applets - 13 teachers, and the ones that used to develop GeoGebra applets together with their students - 11 teachers.

Objectives. The main objective of this research is to examine and assess influence of ICT usage on affectivemotivational characteristics of teachers. Having in mind various possibilities to employ technology in the classroom, we decided to find out if there are differences in the influence levels that different approaches to technology usage in the classroom affect the teachers' characteristics. In other words, our task is to answer the following question: To what extent the way ICT is used in the instruction shapes the teachers' beliefs and attitudes?

Instruments and survey. The participants to the survey filled in a questionnaire consisted of two parts. The first part covered general information about participants - their age, education and work experience. In the second part there were five items statements expressing teacher's beliefs about the instruction process. For every statement teachers could pick one of five assessments representing their attitude about the statement - "I strongly disagree", "I disagree", "I am neutral", "I agree" and "I strongly agree". In order to compare teachers' attitudes and estimate their beliefs, we assigned numerical values to the assessments - 1 for "I strongly disagree" to 5 for "I strongly agree". The statements of the second part of the questionnaire were:

1. I find it easy to prepare teaching materials.

2. Using ICT in Mathematics instruction helps students understand the subject material.

3. Mathematics is easy for students to learn.

4. Relations between my students and me in the classroom are relaxed.

5. I can easily make my students interested in subject material.

Data collection and analysis. All the teachers covered with the survey had similar background - they were all from southern regions of Serbia, mostly with rural background. Their age and work experience varied very slightly between the groups.

We used methods of descriptive statistics (average values; standard deviations) to process general data collected through the survey. In order to statistically estimate differences in attitudes between the groups of teachers, we conducted $t$-tests for every statement.

\section{NUMERICAL RESULTS}

In Tables 1-5 we present data concerning the second part of the questionnaire. Besides, we conduct $t$-tests to compare statistical differences between the groups concerning all five statements. Having in mind $t$ and $p$ values we obtained for all five criteria, we draw conclusions about statistical significance of 
the differences between the groups. We observed statistical differences at 0.05 level.

Table 1. Average values and standard deviations for the first statement.

\begin{tabular}{|l|l|l|l|}
\hline Group & Count & Average & SD \\
\hline 1. & 41 & 2.51 & 1.25 \\
2. & 13 & 3.46 & 1.21 \\
3. & 11 & 3.18 & 1.27 \\
\hline
\end{tabular}

For this statement we obtained following results:

1.1. For the first and the second groups, we have $t=-2.35$, $d f=52, p=0.02$.

1.2. For the first and the third groups, we have $t=-1.54$, $d f=50, p=0.13$.

1.3. For the second and the third groups, we have $t=0.53$, $d f=22, p=0.60$.

The first criterion was about difficulties teachers encounter while preparing teaching materials. The only statistically significant difference was between the first and the second groups, in favor of the second one. It could be expected, considering that the second group of teachers worked with readymade materials. On the other hand, the difference between the second and the third groups was not statistically significant, though the third group teachers had to develop their own applets.

Table 2. Average values and standard deviations for the second statement.

\begin{tabular}{|l|l|l|l|}
\hline Group & Count & Average & SD \\
\hline 1. & 41 & 2.56 & 1.13 \\
2. & 13 & 2.69 & 1.20 \\
3. & 11 & 3.82 & 1.27 \\
\hline
\end{tabular}

For the second statement we obtained following results:

2.1. For the first and the second groups, we have $t=-0.35$, $d f=52, p=0.73$.

2.2. For the first and the third groups, we have $t=-3.14$, $d f=50, p=0.0029$.

2.3. For the second and the third groups, we have $t=-2.14$, $d f=22, p=0.044$.

The second criterion expressed teachers' opinion on influence of ICT usage in the instruction process to students' understanding of materials taught. The differences appeared to be significant between the first and the third, and the second and the third groups, in both cases in favor of the third group. Though the difference between the first and the third groups could be expected, it could be useful to understand why the difference between the second and the third groups was statistically significant, and was not in case $1-2$. The answer lies in the way the second group of teachers used technology in the instruction. Generally, usage of ready-made applets impedes students' creativity which is in direct connection to understanding the subject materials.

Table 3. Average values and standard deviations for the third statement.

\begin{tabular}{|l|l|l|l|}
\hline Group & Count & Average & SD \\
\hline 1. & 41 & 2.85 & 1.12 \\
2. & 13 & 2.92 & 1.27 \\
3. & 11 & 3.27 & 1.35 \\
\hline
\end{tabular}

For the third statement we obtained following results:

3.1. For the first and the second groups, we have $t=-0.19$, $d f=52, p=0.85$.

3.2. For the first and the third groups, we have $t=-1.03$, $d f=50, p=0.31$.

3.3. For the second and the third groups, we have $t=-0.62$, $d f=22, p=0.54$.

The third criterion is teachers' perception on difficulties students meet while learning Mathematics. All three groups of teachers had very similar scores - from 2.85 to 3.27 , and there was no statistically significant difference between any of the groups. This means that teachers expect students can learn Mathematics easily, regardless of the technology used in the instruction process.

Table 4. Average values and standard deviations for the fourth statement.

\begin{tabular}{|l|l|l|l|}
\hline Group & Count & Average & SD \\
\hline 1. & 41 & 2.41 & 1.06 \\
2. & 13 & 3 & 1.24 \\
3. & 11 & 3.91 & 1.16 \\
\hline
\end{tabular}

For the fourth statement we obtained following results:

4.1. For the first and the second groups, we have $t=-1.63$, $d f=52, p=0.11$.

4.2. For the first and the third groups, we have $t=-3.99$, $d f=50, p=0.0037$.

4.3. For the second and the third groups, we have $t=-1.76$, $d f=22, p=0.092$.

The fourth criterion was the nature of the teacher-students relations in the classroom. The difference was statistically significant only between the first and the third groups. Although the second group also used ICT in the classroom, it came out that it did not ease the relations as it did with the third group of the teachers. On the other hand, the difference between the second 
and the third groups, tough very high $(t=-1.76, d f=22$, $p=0.092$ ), was not statistically significant.

Table 5. Average values and standard deviations for the fifth statement.

\begin{tabular}{|l|l|l|l|}
\hline Group & Count & Average & SD \\
\hline 1. & 41 & 2.56 & 1.08 \\
2. & 13 & 2.85 & 1.23 \\
3. & 11 & 4 & 1.13 \\
\hline
\end{tabular}

For the fifth statement we obtained following results:

5.1. For the first and the second groups, we have $t=-0.78$, $d f=52, p=0.44$.

5.2. For the first and the third groups, we have $t=-4.12$, $d f=50, p=0.033$.

5.3. For the second and the third groups, we have $t=-2.28$, $d f=22, p=0.0001$.

Finally, the fifth criterion was teachers' opinion about their ability to make students understand teaching materials. The difference was statistically significant in cases $1-3$ and $2-3$, and in case $1-2$ the difference was not statistically significant. These suggest that teachers are more successful in helping students understand subject materials when they develop GeoGebra applets with students, than in cases when they use ready-made applets or do not use them at all.

A more comprehensive picture can be obtained if all these conclusions are taken together, Table 6 , wherefrom one can see that, comparing to the first two groups of teachers, the third one expresses significantly more positive attitude and beliefs about efficiency of the instruction and their relation to students.

Table 6. Statistical significance of differences between the groups at 0.05 level.

\begin{tabular}{|l|l|l|l|}
\hline $\begin{array}{l}\text { Pair of } \\
\text { groups }\end{array}$ & $1-2$ & $1-3$ & $2-3$ \\
\hline 1. & Yes & No & No \\
2. & No & Yes & Yes \\
3. & No & No & No \\
4. & No & Yes & No \\
5. & No & Yes & Yes \\
\hline
\end{tabular}

\section{CONCLUSIONS AND DISCUSSION}

Introducing GeoGebra applets into the instruction process can alleviate teachers' efforts in preparing mathematics instruction. But the alleviation depends on the type of the applets. Teachers find developing applets more difficult than using ready-made ones.
Teachers that used to develop GeoGebra applets together with their students (the third group) consider their type of instruction helpful for students to understand subject material. On the other hand, those using ready-made applets (the second group) found their students less able to understand the subject material. The difference could be understood taking in consideration cognitive efforts the second group students need to incorporate the mathematics and the technology.

Concerning the teacher-students relations in the classroom, the most relaxed ones were with the third group of the teachers. Though this conclusion sounds similar to what Farrell stated in (1996), it clearly points that a mere introduction of ICT into the instruction process does not necessarily lead to a better interrelationship in the instruction. The reason was obviously the way technology was introduced in the classroom. Time and energy spent in developing the applets and the communication during the process contributes to a friendlier atmosphere in the classroom.

Increasing students' interest for, and their understanding of the subject material is not an easy task for a teacher. Modern day students are very keen of ICT, but different ways we use them in the classroom induce different students' reactions. For that reason, students that took part in developing GeoGebra applets representing mathematical ideas, concepts or procedures showed better understanding of the subject material. Another possibility is that the teachers cooperating with students had better insight into their students' ideas about the subject material.

The research points out that introduction of ICT into mathematics instruction, though a necessity today, has to be carefully organized. The way we use ICT in the instruction impacts many aspects of the teaching/learning process (teachers' preparations of teaching materials, students' interest and understanding, interrelations in the classroom). Introducing ICT in the instruction in a way that requires more student activities and student-teacher cooperation brings more positive results. On the other hand, using ready-made applets can result in lessening teachers' efforts and declining students' commitment to learn, which can be reflected through their achievements and teachers' perceptions.

Finally, the research and its results lead to some questions that need to be addressed in future research. Some of the most important issues following this research are:

- Does the level of difficulty/ease of preparing teaching materials in an ICT environment impact readiness of teachers to cooperate with students and thus initiate fuller engagement of their capacities? If it does, in what manner?

- Can better relations between students and teachers in the classroom, achieved in this way, lead to better academic achievements of students?

- Can the students' interest for the subject material achieved an ICT classroom, organized in a manner the third group of teachers did, be maintained? 


\section{REFERENCES}

Arbain, N., \& Shukor, N. 2015. The effects of GeoGebra on students' achievements, Procedia Social and Behavioral Sciences, 172, pp. 208-214.

Bennett, S., \& Maton, K. 2010. Beyond the 'digital natives' debate: Towards a more nuanced understanding of students' technology experiences. Journal of Computer Assisted Learning, 26, pp. 321-331.

Brown, R. 2010. Does the introduction of the graphics calculator into system-wide examinations lead to change in the types of mathematical skills tested? Educational Studies in Mathematics, 73(2), pp. 181-203.

Bullen, M., Morgan, T., \& Qayyum, A. 2011. Digital Learners in Higher Education: Generation is Not the Issue. Canadian Journal of Learning Technology, 37(1), pp. 1-24.

Döhrmann, M., Kaiser, G., \& Blömeke, S. 2012. The conceptualisation of mathematics competencies in the international teacher education study TEDS-M, ZDM, 44(3), pp. 325-340.

Farrell, A. 1996. Roles and behaviors in technology-integrated precalculus classrooms. Journal of Mathematical behavior, 15, pp. 35-53.

Fuglestad, A. B., Healy, L., Kynigos, C. \& Monaghan, J. 2010. Working with teachers: Context and Culture. In C. Hoyles, and J.-B. Lagrange (Eds.), Mathematics education and technology - rethinking the terrain. The 17th ICMI study, pp. 293-310. Heidelberg: Springer.

Goos, M. \& Lavergne, S., with Assude, T., Brown, J., Kong, C., M., Glover, D., Grugeon, B., Laborde, C., Lavicza, Z., Miller, D., \& Sinclair, M. 2010. Teachers and teaching: Theoretical perspectives and issues concerning Classroom implementation. In C. Hoyles, and J.-B. Lagrange (Eds.), Mathematics education and technology-rethinking the terrain. The 17th ICMI study, pp. 311-328. Heidelberg: Springer.

Hohenwarter, J., Hohenwarter, M., \& Lavicza, Z. 2009. Introducing Dynamic Mathematics Software to Secondary School Teachers: the Case of GeoGebra. Journal of Computers in Mathematics and Science Teaching, 28(2), pp. 135-146. Waynesville, NC USA: Association for the
Advancement of Computing in Education (AACE). Retrieved March 17, 2018 from https://www.learntechlib.org/p/30304/.

Hopper, S. 2009. The effect of technology use on Student interest and understanding in Geometry, Studies in Teaching, Research Digest, pp. 37-42.

Jimoyiannis, A. 2010. Designing and implementing an integrated technological pedagogical science knowledge framework for science teachers' professional development. Computers \& Education, 55(3), pp. 1259-1269. doi: 10.1016/ j.compedu.2010.05.022

Oblinger, D., \& Oblinger, J. 2005. Is it Age or IT: First steps towards understanding the net generation? In: D. Oblinger and J. Oblinger Eds., Educating the Net Generation. (2.12.20). Boulder, CO: EDUCAUSE.

Preiner, J. 2008. Introducing dynamic mathematics software to mathematics teachers: The case of GeoGebra. PhD Thesis, University of Salzburg Austria.

Rajagopal, S., Ismail, Z., Ali, M., \& Sulaiman, N. 2015. Attitude of secondary students towards the use of GeoGebra in learning loci in two dimensions, International Educational Studies, 8(13), pp. 27-32.

Senk, S.L., Tatto, M.T., Reckase, M., Rowley, G., Peck, R., \& Bankov, K. 2012. Knowledge of future primary teachers for teaching mathematics: An international comparative perspective. ZDM - The International Journal on Mathematics Education, 44(3), pp. 307-324.

Tabach, M., Hershkowitz, R., \& Dreyfus, T. 2013. Learning beginning algebra in a computer-intensive environment, The International Journal on Mathematics Education, 45, pp. 377 391.

Tatar, E. 2013. The effect of dynamic software on prospective mathematics teachers' perceptions regarding information and communication technology, Australian Journal of Teacher Education, 38(12), pp. 1-16.

White, D.S., \& Le Cornu, A. (2011). Visitors and Residents: A new typology for online engagement. First Monday, 16, pp. 9-15.

Zakaria, E., \& Lee. L. S. 2012. Teachers' perceptions towards the use of GeoGebra in the teaching and learning Mathematics, Journal of Mathematics and Statistics, 8(2), pp. 253-257. 